\title{
On-Farm Diversity of Common Bean (Phaseolus Vulgaris L.) Varieties in East Hararghe Zone, Eastern Ethiopia
}

\author{
Sate Sahle ( $\nabla$ seatesahle@gmail.com ) \\ Tamado Tana \\ University of Eswatini Faculty of Agriculture \\ Nigussie Dechassa \\ Haramaya University \\ Habtamu Zeleke \\ Haramaya University
}

Haramaya University College of Agricultural and Environmental Sciences https://orcid.org/0000-0002-4303-6447

\section{Research Article}

Keywords: Common bean, land size, relative wealth, value

Posted Date: April 7th, 2021

DOI: https://doi.org/10.21203/rs.3.rs-353097/v1

License: (c) This work is licensed under a Creative Commons Attribution 4.0 International License. Read Full License

Version of Record: A version of this preprint was published at Genetic Resources and Crop Evolution on October 29th, 2021. See the published version at https://doi.org/10.1007/s10722-021-01281-7. 


\section{Abstract}

Common bean (Phaseolus vulgaris L.) is an important source of food and income. However, its on-farm diversity and conservation by smallholder farmers is not known in the east Hararghe Zone of eastern Ethiopia. Thus, field survey was conducted from November 2018 to February 2019 to assess the on-farm diversity, cropping system and the role of gender in production and management of common bean varieties. Common bean producing districts were selected purposively whereas sub-districts (kebeles) were selected randomly. Three kebeles from each of the two major agro-ecological zones, two key informants and twelve general informants from each kebele were selected to constitute a total of 84 informants. The selection of general informants was stratified based on gender and wealth status. Structured interview guide was used to interview general informants whereas semi-structured interview guide was used to interview key informants. Descriptive and inferential statistical analyses were conducted in $R$ (version 3.5.2). Seven farmers' varieties of common bean were identified of and their diversity was higher in tepid, moist mid highlands (M3) whereas cropped area (ha) was significantly $(p<0.05)$ higher in tepid sub-humid highlands (SH3) agro-ecology. Most activities of common bean were undertaken by male adults. Insect pests were the prominent constraints of common bean production. Farmers' varieties were used as food and feed, and soil fertility management. Therefore, their on-farm and ex situ conservation, maintenance of endangered varieties, and shortage of cropping land due to chat plantation need special concern to promote their cultivation.

\section{Introduction}

Common bean is among major food legumes and ranks third as one of the most important worldwide food crops next to soybean and peanut in terms of production (Jibril et al. 2015). It is cultivated in a wide range of agro-ecologies and farming systems including well-watered and drought-stressed areas (Asrat et al. 2011). Common bean is a widely adaptable, warm-season herbaceous plant with distribution in tropical, subtropical, and temperate environments (Heuzé et al. 2015). It can be cultivated in diverse types of soils, but ideally in well-drained silt loam, sandy loam or clay loam soils with high organic content and a pH between 4 and 9 (Ecoport 2013).

P. vulgaris $\mathrm{L}$. $(2 \mathrm{n}=2 \mathrm{x}=22)$ belongs to the Fabaceae family, which comprises species displaying a wide variety of forms: trees, shrubs and herbs, including many with a climbing growth habit (Porch et al. 2013). It is one of the most important legume crops grown in all continents of the world except Antarctica, because of its high protein, fiber, and complex carbohydrate content. Beans (Phaseolus spp.) are extremely diverse crops in terms of cultivation methods, in diverse environments and elevations ranging from sea level to $3,000 \mathrm{~m}$ height, morphological variability, and utilities (dry as pulse and green as vegetable) (Pathania et al. 2006).

Its production contributes both as food, fodder for livestock, export commodity and serves as a source of income and employment to a large supply chain and for risk aversion strategies to poor farmers during drought due to early maturity and moderate degree of drought tolerance (Darkwa et al. 2016). As a legume, it provides nitrogen and other soil health benefits under cropping system to subsequently grown crops.

Common bean production has been practiced in all regions of Ethiopia (Menbere 2017). However, the major common bean producing areas are central, eastern and southern parts of the country (Hirpa et al. 2013). White and red types are commonly cultivated in the country. They occupied $78,910.13$ and $211,212.30$ hectares of land and produced $125,980.175$ and $357,942.475$ tonnes of grain, respectively, during 2016/17 main cropping season (CSA 2017). These two types of common bean share $18.72 \%$ of land area and $17.2 \%$ of yield contributed by all pulse crops in the country (CSA 2017).

In eastern Hararghe Zone, common bean is 1 st in area of production (3,593.21 ha) and productivity among the pulse crops (CSA 2016). It is an important source of protein, source of cash, emergency crop, and well suited for multiple cropping systems with maize and sorghum.

Among common bean growing countries in Africa, Ethiopia is considered to grow many varieties of the crop (Tura et al. 2018). The immense genetic diversity of landraces of crops is the most directly useful and economically valuable part of biodiversity (Jose et al. 2014). Unlike high yielding varieties, the landraces maintained by farmers are endowed with tremendous genetic variability, as they are not subjected to subtle selection over a long period.

Even though the productivity of farmers' varieties is lower than improved varieties, their local demand is often high because they are required for the preparation of cultural foods and they are more reliable under a wider range of conditions (Bethelem et al. 2020). In addition, Farmers' traditional varieties, or landraces, have been selected for specific agro-ecological niches and in some cases have been shown to better resist insect pests, diseases and climate shocks, as well as meet the nutritional and cultural needs of Ethiopia's diverse farming communities (Tigist et al. 2018). Despite the significance of Ethiopia's legume diversity, it remains largely unstudied and unmonitored (Ruelle et al. 2019) in general and in east Haraghe Zone in particular. Studies done on common bean so far in the country focused on adoption, agronomic aspects, breeding, and disease resistance aimed at increasing yield (Agete 2014).

Therefore, this study was undertaken to assess the on-farm diversity and cropping system of common bean, and to assess traits, values and the role of gender in production and management of common bean varieties in east Hararghe Zone.

Page 2/21 


\section{Methodology}

\subsection{Description of Study Area}

A field survey was conducted in east Hararghe Zone to collect basic information on common bean production and cropping systems adopted by the local farmers. The geographical location of east Hararghe Zone ranges from $7^{\circ} 30^{\prime}-9^{\circ} 45^{\prime} \mathrm{N}$ latitude and $41^{\circ} 10^{\prime}-42^{\circ} 50^{\prime} \mathrm{E}$ longitude with altitude ranging from 500-3040 meter above sea level (Mengesha 2015). The zone has two rainy seasons, the short rainy season and the main rainy season, with a mean annual rainfall ranging from $400 \mathrm{~mm}$ in the lowlands to nearly $2000 \mathrm{~mm}$ at higher altitudes. The area has a temperature ranging from $10^{\circ} \mathrm{C}$ to $25^{\circ} \mathrm{C}$ (Tesfaye 2013). The major annual crops grown in the zone include sorghum, maize, common bean, lentil, wheat and barley. The zone has the population of 2,723,850 (CSA 2007) and an area of 22,622.6 $\mathrm{km}^{2}$ (Titay et al. 2021).

\subsection{Sampling Method and Sample Size}

Purposive selection of potential common bean producing districts (Woredas) and random selection of peasant associations (kebeles) were done to collect the valuable information. Accordingly, Haramaya, Qersa, Kombolicha and Meta districts were used for the study since they are major producers of common bean in M3 (tepid moist mid highlands) and SH3 (tepid sub-humid highlands) agro-ecological zones (EHZAO 2017). Three kebeles from each major agro-ecological classification, two key informants and twelve general informants from each kebele were included which constituted a total of 84 informants ( 72 for household survey and 12 for key informant). The selection of general informants was randomly made whereas the selection of key informants was purposive based on their experience in production of common bean. Twelve households (general informants) from each kebele were stratified based on gender and wealth status and thus 3 men from high income households, 3 men from low income households, 3 women from high income households and 3 women from low income households were randomly selected.

\subsection{Data Collection}

Data were collected through structured and semi-structured interview guides. Structured interview guide was used to interview general informants by ODK (Open Data Kit) installed on smart phone whereas semi-structured interview guide was used to interview key informants. Language translators were used to interview the local farmers.

Data of basic information, market access, inter-specific diversity of legume crops, uses of common bean, cropping practices, intra-specific diversity of common bean, key attributes of common bean varieties, rating of attributes, and gender roles in production and management of common bean were collected through structured and semi-structured interview guides.

\subsection{Data Analysis}

Interview data were compiled and cross-tabulated for graphic visualization in MS Excel. Descriptive and inferential statistical analyses and were conducted in $\mathrm{R}$ (version 3.5.2). A two-factor analysis of variance (ANOVA) was conducted to determine whether there were significant differences in the area planted to agro-ecological zone and closest market time to Woreda, followed by a post hoc Tukey test to identify pair-wise significant differences. Shannon Diversity Index (SDI) analysis was employed to observe the diversity of common bean varieties across the study kebeles and agro-ecological zones following the diversity analysis method (Shannon and weaver 1948) as follows:

$$
H=\frac{-\sum p_{i} \ln p_{i}}{\ln n}
$$

Where $\mathrm{p}_{\mathrm{i}}$ is the proportion of the total number of varieties in the $\mathrm{i}^{\text {th }}$ class and $n$ is the number of households producing common bean.

\section{Results And Discussion}

\subsection{Variety Identification and Diversity}

Farmers identified seven common bean varieties based on their own criteria such as seed color and size (Table 1). The richness and diversity of varieties varied across kebeles and agro-ecological zones. Shannon Diversity Index (SDI) analysis was employed to observe the diversity of common bean varieties across the study kebeles. Accordingly, it was higher at Damota (1.00) in 2017 cropping season (Table 1). Similarly, it was higher (1.03) at Yabeta Selama in 2018. In contrast, its values were nil at Duresitu Bilisuma kebele for both cropping seasons and Egu kebele in 2017 cropping season because Adi and Dima were the only varieties reported to exist at former and later kebeles, respectively. This variation in diversity might be due to differences in seed accessibility, lack of awareness and income level of farmers. Menbere (2017) also reported significant difference in Shannon diversity across different strata and the highest value (1.33) was recorded under M2 (Warm, Moist 
Lowlands) agro-ecology of south Wollo in Amhara region. Similarly, Bethelem et al. (2020) also reported highest value (1.74) of Shannon diversity index in Bench Maji and Sheka administrative Zones at H3 (tepid, mid-highlands) agro-ecology as compared to others.

Table 1

Name of farmers' variety, identification criteria, agro-ecology and Shannon Diversity Index of common bean in east Hararghe Zone in 2017 and 2018.

\begin{tabular}{|c|c|c|c|c|c|c|c|}
\hline & & & & & & SDI & \\
\hline Kebele & Name of farmers 'variety & Identification criteria & Recognition & AEZ & Altitude range(masl) & 2017 & 2018 \\
\hline \multirow[t]{5}{*}{ Damota } & Adi & Seed color & White seed & \multirow[t]{5}{*}{ M3 } & \multirow[t]{5}{*}{ 2071.45-2116.77 } & \multirow[t]{5}{*}{1.00} & \multirow[t]{5}{*}{1.02} \\
\hline & Adi bosolia & Seed color and size & White and big seed & & & & \\
\hline & Bure & Seed color & Spotted gray seed & & & & \\
\hline & Dima & Seed color & Red seed & & & & \\
\hline & Dima ashongore & Seed color and size & Red and big seed & & & & \\
\hline $\begin{array}{l}\text { Duresitu } \\
\text { Bilisuma }\end{array}$ & Adi & Seed color & White seed & $\mathrm{SH} 3$ & 2095.67-2207.52 & 0 & 0 \\
\hline \multirow[t]{2}{*}{ Egu } & Adi & Seed color & White seed & \multirow[t]{2}{*}{ M3 } & \multirow[t]{2}{*}{ 2173.99-2204.53 } & \multirow[t]{2}{*}{0} & \multirow[t]{2}{*}{0.06} \\
\hline & Dima & Seed color & Red seed & & & & \\
\hline \multirow[t]{3}{*}{ Haro Ariba } & Adi & Seed color & White seed & \multirow[t]{3}{*}{$\mathrm{SH} 3$} & \multirow[t]{3}{*}{$2141.97-2175.37$} & \multirow[t]{3}{*}{0.68} & \multirow[t]{3}{*}{0.80} \\
\hline & Dalecha & Seed color & Cream seed & & & & \\
\hline & Dima & Seed color & Red seed & & & & \\
\hline \multirow[t]{3}{*}{ Kuro } & Adi & Seed color & White seed & \multirow[t]{3}{*}{ M3 } & \multirow[t]{3}{*}{ 2041.39-2123.44 } & \multirow[t]{3}{*}{0.61} & \multirow[t]{3}{*}{0.61} \\
\hline & Bure & Seed color & Spotted gray seed & & & & \\
\hline & Dima & Seed color & Red seed & & & & \\
\hline \multirow[t]{4}{*}{ Yabata Selama } & Adi & Seed color & White seed & \multirow[t]{4}{*}{$\mathrm{SH} 3$} & \multirow[t]{4}{*}{ 2009.19-2034.89 } & \multirow[t]{4}{*}{0.97} & \multirow[t]{4}{*}{1.03} \\
\hline & Adi bosolia & Seed color and size & White and big seed & & & & \\
\hline & Dima & Seed color & Red seed & & & & \\
\hline & Jiner & Seed color & Gray seed & & & & \\
\hline
\end{tabular}

NB: SDI = Shannon Diversity Index, masl = meter above sea level, AEZ = Agro-ecological zone, M3 = tepid, moist mid highlands, SH3 = tepid, subhumid mid highlands

The three diversity indices of common bean varieties were higher in M3 (tepid, moist mid highlands) agro-ecology as compared to SH3 (tepid, sub-humid mid highlands) agro-ecology (Table 2). The variation of diversity in varieties might be due to differences in market access and seed availability. Contrary to this result, Bethlehem et al. (2020) reported highest value of Shannon diversity index in H3 (tepid, mid-highlands) agroecology as compared to others.

Table 2

Diversity Indices of Common Bean in M3 and SH3 Agro-ecologies in east Hararghe Zone in 2017 and 2018

\begin{tabular}{|llll|}
\hline \multirow{2}{*}{ Agro-ecology } & \multicolumn{3}{c|}{ Diversity index } \\
\cline { 2 - 4 } & alpha & gamma & beta \\
\hline Tepid moist mid highlands (M3) & 1.44 & 6 & 4.15 \\
\hline Tepid sub-humid highlands (SH3) & 1.33 & 5 & 3.75 \\
\hline
\end{tabular}

\subsection{Facilities and Factors of Common bean Production}

\subsubsection{Wealth}

Two sample t-test showed that the cropped area of common bean was not significantly $(p=0.05436)$ affected by the wealth group of the farmers in 2017 cropping season. Contrary to this, it was significantly ( $p=0.004988)$ affected by wealth group in 2018 cropping season 
(Table 3). Cropped area of common bean was higher in mid-to-high income group ( $0.25 \mathrm{ha})$ as compared to low income group possibly due to more land availability and income level to buy the seed by mid-to-high income group farmers. In line with this result, Betelhem et al. (2020) reported that the area planted to common bean by smallholder farmers in Bench Maji, Sheka, Kafa, east Gojjam and south Wollo zones was significantly affected by the relative wealth categories in 2015/16 cropping season in which mid-to-high income households planted significantly more common bean than low income households ( 0.39 ha compared to 0.29 ha).

Table 3

Mean value of cropped area (ha) as affected by wealth group of farmers in east Hararghe Zone in 2017 and 2018 $(n=72)$

\begin{tabular}{|lcc|}
\hline \multicolumn{2}{|c|}{ Year } \\
\hline Wealth group & 2017 & 2018 \\
\hline Low & $0.15 \mathrm{a}$ & $0.16 \mathrm{~b}$ \\
\hline Mid to high & $0.22 \mathrm{a}$ & $0.25 \mathrm{a}$ \\
\hline Means followed by the same letters are not significantly different according to t-test at 5\% level of significance. \\
\hline
\end{tabular}

\subsubsection{Agro-Ecology}

Common bean growing area was not significantly $(p=0.063)$ different in the M3 and SH3 agro-ecological zones in 2017 cropping season, but it was significantly $(p<0.001)$ varied by the agro-ecologies during 2018 cropping season and higher value $(0.28$ ha) was recorded in SH3 (Table 4). This higher value of cropped area might be due to good growing conditions for common bean in this agro-ecology. It was also significantly $(p<0.001)$ varied among kebeles in 2017 and 2018 cropping seasons (Table 4). The highest area of production was recorded at Yabeta Selama kebele both in 2017 (0.34 ha) and 2018 (0.39 ha) probably due to variation in land availability, income level and soil fertility status. In agreement with this result, Menbere (2017) reported significant difference in cropped area due to administrative zones and agroecologies in which higher area was recorded in east Gojjam zone (0.45 ha) and M3 agro-ecology (0.54 ha). Betelhem et al. (2020) also reported significant differences in cropped area in which on average, households in East Gojjam zone planted more land to common bean ( 0.57 ha), followed by South Wollo (0.43 ha), Kefa (0.20 ha), and Bench Maji and Sheka (0.14 ha).

Table 4

Mean cropped area (ha) of common bean per household as affected by kebele and agro-ecology in east Hararghe zone in 2017 and 2018

\begin{tabular}{|lll|}
\hline Kebele & \multicolumn{2}{l|}{ Cropped area (ha) } \\
\cline { 2 - 3 } & 2017 & 2018 \\
\hline Kuro & $0.11 \mathrm{~b}$ & $0.11 \mathrm{~b}$ \\
\hline HaroAriba & $0.12 \mathrm{~b}$ & $0.21 \mathrm{~b}$ \\
\hline Damota & $0.15 \mathrm{~b}$ & $0.15 \mathrm{~b}$ \\
\hline Duresitu Bilisuma & $0.19 \mathrm{ab}$ & $0.19 \mathrm{~b}$ \\
\hline Egu & $0.22 \mathrm{ab}$ & $0.20 \mathrm{~b}$ \\
\hline Yabeta Selama & $0.34 \mathrm{a}$ & $0.39 \mathrm{a}$ \\
\hline P value & 0.001 & 0.00004 \\
\hline Agro-ecology & & \\
\hline $\begin{array}{l}\text { Tepid, moist mid highlands } \\
\text { (M3) }\end{array}$ & $0.16 \mathrm{a}$ & $0.15 \mathrm{~b}$ \\
\hline $\begin{array}{l}\text { Tepid, sub-humid highlands } \\
\text { (SH3) } \\
\text { SH3 }\end{array}$ & $0.22 \mathrm{a}$ & $0.26 \mathrm{a}$ \\
\hline \begin{tabular}{l} 
P value \\
\hline
\end{tabular} & & \\
\hline area and & 0.063 & 0.0005 \\
\hline
\end{tabular}

NB: The cropped area includes the sole crop area and under intercropping. Means followed by the same letters are not significantly different according to Post Hoc Tukey's test $(a=0.05)$. ha = hectare, Kebele= sub-district

Time required to the nearest road (by walking) was not significantly ( $p>0.05$ ) different among the Woredas and agro-ecologies in $2017 / 18$ (Table 5). But the time required to the closest market (by vehicle) was significantly $(p<0.05)$ different among the Woredas as well as agro-

Page 5/21 
ecology (Table 5). The highest time to the closest market (47.2 minutes) was recorded in Meta while the lowest time (19.3 minutes) was recorded in Haramaya Woreda. Likewise, significantly higher time (23.2 minutes) was recorded in tepid, sub-humid highlands (SH3) agro-ecology over tepid, moist mid highlands (M3) agro-ecology. This might be due differences in topography and road facility across the Woredas and agroecologies.

Table 5

Time to closest market and road (minutes) as affected by Woreda and agro-ecology in east Hararghe Zone $(n=72)$

\begin{tabular}{|lll|}
\hline Woreda & Minutes to closet market & Minutes to road \\
\hline Haramaya & $19.3 \mathrm{c}$ & 4.29 \\
\hline Kombolicha & $30.8 \mathrm{~b}$ & 5.79 \\
\hline Meta & $47.2 \mathrm{a}$ & 6.08 \\
\hline Qersa & $8.3 \mathrm{ab}$ & 7.42 \\
\hline P value & $1.12 \times 10^{-8}$ & $0.45 \mathrm{~ns}$ \\
\hline Agro-ecology & & 4.89 \\
\hline M3 & $23.2 \mathrm{~b}$ & 6.33 \\
\hline SH3 & $41.3 \mathrm{a}$ & $0.28 \mathrm{~ns}$ \\
\hline P value & $6.27 \times 10^{-8}$ & \\
\hline Woreda = district, M3 = tepid, moist mid highlands, SH3 = tepid, sub-humid highlands, ns = not significant at $5 \%$ probability level. \\
\hline
\end{tabular}

Means followed by the same letter are not significantly different according to Post Hoc Tukey test $(a=0.05)$.

\subsubsection{Seed source}

Different seed sources of common bean varieties such as market, family, food-aid, formal and neighbors were reported by the respondents (Table 6). About 37.5 and $34.7 \%$ of the respondents reported that market was the main source of Dima and Adivarieties, respectively. Only few respondents (13.9\%) mentioned that formal seed sources such as University and Office of Agriculture served as seed source for Adivariety. The higher dependence of farmers on market as seed source might be due to shortage of land and low production of the local varieties. In contrast to this finding, Tura et al. (2018) reported that many farmers did not purchase common bean seed from market.

Table 6

Proportion of general respondents and seed sources of common bean varieties in east Hararghe Zone $(\mathrm{n}=72)$

\begin{tabular}{|llllll|}
\hline Variety & \multicolumn{5}{c|}{ Seed source } \\
\hline Fdi & Family & Food aid & Formal & Market & Neighbors \\
\hline Adi bosolia & 1 & 1 & 10 & 25 & 0 \\
\hline Bure & 6 & 0 & 2 & 1 & 0 \\
\hline Dalecha & 1 & 0 & 0 & 0 & 0 \\
Dima & 13 & 0 & 1 & 27 & 2 \\
\hline Dima ashongore & 1 & 0 & 0 & 0 & 0 \\
\hline Jiner & 0 & 0 & 0 & 1 & 0 \\
\hline
\end{tabular}

\subsubsection{Growing experience}

The identified varieties of common bean were grown by the respondent farmers for varied years (Fig. 2). Accordingly, greater number of respondents (37.5\%) used to grow Dima variety for more than ten years. Few respondents also reported that varieties such as Jiner, Dima ashongore and Bure were grown for more than ten years. However, some key informants reported that the growing area of most common bean varieties since last five years was getting low due to land shortage and large area covered by chat plant. They also informed that varieties such as Bure, Jiner and Dalecha were endangered and their cultivation was less common in the community currently possibly due to less demand as a source of food and market. In addition, the adaptability of these varieties grown in the study area might be less. Furthermore, less attention might have been given for biodiversity conservation for these endangered varieties. In agreement with this result, Menbere (2017) reported 
variability in market demand among the varieties of common bean. Similarly, Tura et al. (2018) also reported that the dominance of a given variety is associated with market and use values.

\subsubsection{Agronomic management}

\subsubsection{Time of sowing}

The response of respondent farmers showed that common bean varieties were sown in different months of the year (Table 7). Greater number of the respondents (16.6\% and $12.5 \%$, respectively) reported that Adi and Dima varieties were sown at the end of June. The preference of farmers sowing in this time might be due to the dependence attributed to the onset of the rainfall. According to the majority of key informants (83.3\%), Dima variety can be grown two times in a year based on the availability of rainfall. Zelalem (2015) also reported that the sowing seasons of common bean varieties vary following the amount and onset of rain. Asrat et al. (2013) also indicated that cropping practices in common bean production vary depending on the reliable rainfall in which many farmers of Amaro and Konso plant larger areas with common bean during 'Belg' while many farmers in Boricha and Loma plant larger areas in the 'Meher' season.

Table 7

Proportion of general respondents and sowing time of common bean varieties in east Hararghe Zone $(n=72)$

\begin{tabular}{|c|c|c|c|c|c|c|c|}
\hline \multirow[t]{2}{*}{ Sowing time (month) } & \multicolumn{7}{|c|}{ Variety } \\
\hline & Adi & $\begin{array}{l}\text { Adi } \\
\text { bosolia }\end{array}$ & Bure & Dalecha & Dima & $\begin{array}{l}\text { Dima } \\
\text { ashongore }\end{array}$ & Jiner \\
\hline End of March & 1 & 0 & 0 & 1 & 1 & 0 & 0 \\
\hline Beginning of April & 4 & 2 & 4 & 0 & 3 & 1 & 0 \\
\hline Mid-April & 1 & 0 & 0 & 0 & 11 & 0 & 0 \\
\hline End of April & 0 & 0 & 0 & 0 & 1 & 0 & 0 \\
\hline Beginning of June & 2 & 0 & 0 & 0 & 0 & 0 & 0 \\
\hline Mid-June & 2 & 0 & 1 & 0 & 2 & 0 & 1 \\
\hline $\begin{array}{l}\text { Mid-June to beginning } \\
\text { of July }\end{array}$ & 0 & 0 & 0 & 0 & 1 & 0 & 0 \\
\hline End of June & 12 & 0 & 0 & 0 & 9 & 0 & 0 \\
\hline $\begin{array}{l}\text { End June to beginning } \\
\text { of July }\end{array}$ & 3 & 0 & 0 & 0 & 0 & 0 & 0 \\
\hline Beginning of July & 7 & 0 & 0 & 0 & 2 & 0 & 0 \\
\hline Mid July & 2 & 0 & 0 & 0 & 0 & 0 & 0 \\
\hline Beginning of August & 1 & 0 & 0 & 0 & 0 & 0 & 0 \\
\hline
\end{tabular}

\subsubsection{Time of harvesting}

Sixteen different harvesting times were indicated by the respondents of which the majority (20.8\%) reported that Adivariety was harvested at the beginning of October (Table 8). Some of the respondents mentioned that, sometimes based on the onset of rainfall, they practice sowing Dima variety at the end of March or beginning of April and harvest beginning from mid-June to mid-July. This might be due differences in sowing time and differences in maturity of the varieties. Teame et al. (2017) also reported significantly different time of harvesting of common bean varieties at Mehoni Agricultural Research center, Raya Valley, Northern Ethiopia. Awel et al. (2021) also reported differences in maturity of common bean varieties in which Ser119 matured in shorter time while Variety Dame took the highest time to mature in Kafa and Sheka zones of SNNPR. 
Table 8

Proportion of general respondents and harvesting time (month) of common bean varieties in east Hararghe Zone $(\mathrm{n}=72$ )

\begin{tabular}{|c|c|c|c|c|c|c|c|}
\hline \multirow[t]{2}{*}{ Harvesting time (month) } & \multicolumn{7}{|c|}{ Variety } \\
\hline & Adi & Adi bosolia & Bure & Dalecha & Dima & Dima asongore & Jiner \\
\hline Mid-June & 1 & 0 & 0 & 1 & 1 & 0 & 0 \\
\hline End of June & 0 & 0 & 2 & 0 & 3 & 0 & 0 \\
\hline Beginning of July & 3 & 2 & 2 & 0 & 1 & 1 & 0 \\
\hline Mid July & 0 & 0 & 0 & 0 & 9 & 0 & 0 \\
\hline End of July & 1 & 0 & 0 & 0 & 20 & & 0 \\
\hline Beginning of August & 1 & 0 & 0 & 0 & 0 & 0 & 0 \\
\hline Mid-September & 1 & 0 & 0 & 0 & 0 & 0 & 0 \\
\hline End of September & 1 & 0 & 1 & 0 & 2 & 0 & 0 \\
\hline End of September to beginning of October & 2 & 0 & 0 & 0 & 0 & 0 & 0 \\
\hline Beginning of October & 15 & 0 & 0 & 0 & 6 & 0 & 1 \\
\hline Beginning of October to mid-October & 2 & 0 & 0 & 0 & 0 & 0 & 0 \\
\hline Mid October & 4 & 0 & 0 & 0 & 2 & 0 & 0 \\
\hline End of October & 2 & 0 & 0 & 0 & 1 & 0 & 0 \\
\hline End of October to beginning of November & 2 & 0 & 0 & 0 & 1 & 0 & 0 \\
\hline Beginning of November & 0 & 0 & 0 & 0 & 1 & 0 & 0 \\
\hline End of November & 0 & 0 & 0 & 0 & 1 & 0 & 0 \\
\hline
\end{tabular}

\subsubsection{Crop rotation and intercropping}

Of the rotation crops with common bean varieties mentioned by the respondent farmers, sorghum was given the highest value (Table 9 ).

Conversely, the least values were reported for faba bean and fenugreek as rotation crop with common bean varieties. The preference of common bean to rotate after cereals might be to restore the depleted soil nutrients especially nitrogen which is mostly exhausted by the cereals. Betelhelm et al. (2020) also reported that almost all farmers that grow common bean rotate common bean with other crops such as maize, teff, barley and wheat.

Table 9

Proportion of general respondents, rotation crops and intercropping species with common bean in east Hararghe Zone $(n=72$

\begin{tabular}{|lcl|}
\hline Rotation crop & Frequency & Percent (\%) \\
\hline Carrot & 3 & 4 \\
\hline Faba bean & 1 & 1 \\
\hline Fenugreek & 1 & 1 \\
\hline Maize & 28 & 39 \\
\hline Onion & 13 & 18 \\
\hline Potato & 10 & 14 \\
\hline Sorghum & 33 & 46 \\
\hline Intercropping species & \\
\hline Chat & 13 & 18 \\
\hline Maize & 46 & 64 \\
\hline Sorghum & 46 & 64 \\
\hline
\end{tabular}


Maize and sorghum were equally important as an intercrop (64\%) whereas only $18 \%$ of the respondents mentioned chat as an intercrop with common bean (Table 9). The preference of common bean as an intercrop might be due to its compatibility to grow as an understory crop with other crops even in a small piece of land. Betelehem et al. (2020) also reported that majority of farmers in Benchi-Maji, Sheka and Kefa Zones use maize to grow in intercrops with common bean and sorghum in south Wollo and east Gojjam Zones.

\subsubsection{Marketing practice}

Respondent farmers in the study area practiced to sell the seed of common bean varieties they produce in the market (Fig. 3). The seed of all varieties they grew were sold in the market. Most respondent farmers sell the seed of Dima and Adi varieties (59.7\% and $58.3 \%$, respectively). Only few respondents used to sell the seed of Jiner, Dima ashongore and Dalecha in the market. This might be due differences in market demand and low amount of seed production from local varieties. The report of Tura et al. (2018) agrees with this finding that many farmers produce small quantity of seeds from landraces targeting only their home consumption.

\subsubsection{Growing seasons}

Majority of the respondents (48.6\%) reported that Adivariety was grown once a year from end of June to beginning of October (Fig. 4). On the other hand, Dima variety was grown twice a year beginning from mid-April to mid of June and from end of June to the end of October. All varieties under study were grown at least once a year probably because of lack of conducive weather condition to double or triple the cultivation of common bean varieties in a year. In line with this result, Menbere (2017) also reported that all common bean varieties were grown once a year in main growing season (Meher) in east Gojjam and south Wollo zones.

\subsubsection{Yielding status}

The majority of respondents perceived that the yield of both Adi (40.3\%) and Dima (33.3\%) varieties were low in 2017 and 2018 cropping seasons as compared to previous years (Table 10). The low yield of these varieties might be due to the shortage of moisture, change in climatic condition and prevalence of diseases and insect pests. Similar results were reported by Menbere (2017) that lower yields of common bean varieties were obtained in 2015 than in 2016 growing season which was attributed to the shortage of moisture (drought) in the latter. Amanuel et al. (2018) also reported significant difference in seed yield of common bean cultivars due to the interaction effect of cultivars by $P$ rate in 2016 cropping season in which Tatu gave highest seed yield whereas Remeda gave the lowest seed yield (kg/ha).

Table 10

Proportion of general respondents and yielding status of common bean varieties in east Hararghe Zone $(n=72)$

\begin{tabular}{|lllll|}
\hline Variety & \multicolumn{4}{c|}{ Yielding status } \\
\hline Adi & 2 & Lery low & Medium & High \\
\hline $\begin{array}{l}\text { Adi } \\
\text { bosolia }\end{array}$ & 0 & 29 & 10 & 1 \\
\hline Bure & 2 & 4 & 0 & 0 \\
\hline Dalecha & 0 & 6 & 0 & 0 \\
\hline Dima & 2 & 1 & 0 & 0 \\
\hline $\begin{array}{l}\text { Dima } \\
\text { ashongore }\end{array}$ & 0 & 24 & 16 & 1 \\
\hline Jiner & 0 & 0 & 1 & 0 \\
\hline
\end{tabular}

\subsection{Attributes of Common bean Varieties}

\subsubsection{Tolerance to drought}

According to respondent farmers, the identified varieties of common bean showed differences in response to drought during 2017 and 2018 cropping seasons (Table 11). About 55.5\% of respondents reported that Dima variety showed low tolerance to drought. The susceptibility of Dima variety to drought might be due to the lack of minimum amount of soil moisture to support its growth. Similarly, Menbere (2017) reported that all common bean varieties under study in Amhara region were highly affected by drought. 
Table 11

Proportion of general respondents and tolerance of common bean varieties to drought in east Hararghe Zone ( $\mathrm{n}$ $=72$ )

\begin{tabular}{|lllll|}
\hline Variety & \multicolumn{3}{l|}{ Drought tolerance } & \\
\hline & None & Very low & Low & Medium \\
\hline Adi & 1 & 3 & 37 & 1 \\
\hline Adi bosolia & 0 & 0 & 4 & 0 \\
\hline Bure & 0 & 1 & 7 & 0 \\
\hline Dalecha & 0 & 0 & 1 & 0 \\
\hline Dima & 0 & 2 & 40 & 1 \\
\hline Dima ashongore & 0 & 0 & 1 & 0 \\
\hline Jiner & 0 & 0 & 1 & 0 \\
\hline
\end{tabular}

\subsubsection{Response to water logging}

Majority of respondents reported that Dima (55.5\%) and Adi variety (47.2\%) gave low yield in response to water logging, respectively (Table 12). This result might be due to differences in tolerance level of common been varieties to the stress of waterlogging since common bean is a lowland pulse crop. Contrary to this result, Menbere (2017) reported that waterlogging was not a problem on the yield of common bean.

Table 12

Proportion of general respondents and response of common bean varieties to waterlogging in east Hararghe Zone $(\mathrm{n}=72)$

\begin{tabular}{|lllll|}
\hline Variety & \multicolumn{4}{l|}{ Response to waterlogging } \\
\hline Adi & Very low & Low & Medium & High \\
\hline Adi bosolia & 3 & 34 & 3 & 2 \\
\hline Bure & 0 & 4 & 0 & 0 \\
\hline Dalecha & 0 & 8 & 0 & 0 \\
\hline Dima & 0 & 1 & 0 & 0 \\
\hline Dima ashongore & 0 & 1 & 0 & 0 \\
\hline Jiner & 2 & 40 & 1 & 0 \\
\hline
\end{tabular}

\subsubsection{Resistance to Frost}

Majority of respondent farmers (55.5\%) reported that Adi variety was never affected by the prevalence of frost in the study area (Table 13 ) which might be due the adaptation of varieties to tolerate frost or due to early maturation of the varieties before the onset of the frost which normally occurs in October in east Hararghe Zone. Contrary to this finding, Menbere (2017) reported that none of the varieties under study was affected by frost. 
Table 13

Proportion of general respondents and response of common bean varieties to frost in east Hararghe Zone $(n=72)$

\begin{tabular}{|lllll|}
\hline Variety & & \multicolumn{3}{c|}{ Response } \\
\hline Adi & Never affected & Rarely affected & Sometimes affected & Often affected \\
\hline Adi bosolia & 2 & 0 & 1 & 1 \\
\hline Bure & 6 & 1 & 1 & 0 \\
\hline Dalecha & 1 & 1 & 1 & 0 \\
\hline Dima & 34 & 0 & 0 & 0 \\
\hline Dima ashongore & 1 & 2 & 6 & 1 \\
\hline Jiner & 1 & 0 & 0 & 0 \\
\hline
\end{tabular}

\subsubsection{Resistance to diseases}

The response of common bean varieties to disease occurrence was differently reported by the respondent farmers in the study area (Fig. 5). Accordingly, a greater number of respondents replied that Adi variety was often and sometimes affected by disease. On the other hand, only few respondents reported that Dima variety (15.3\%) was never affected by the disease. Based on their long-time experience and deep knowledge, key informants mentioned the diseases affecting common bean production include Sharuf (Oroomifa) (white mold) and Wag (Amharic) (rust). This might be due to differences in adaptation and tolerance of varieties to disease. Menbere (2017) also reported disease as one of the common problems of common bean production in Amhara National Regional state. Asrat et al. (2013) also reported diseases (rust and angular leaf spot) as an important constraint of common bean production in Boricha, Loma, Amaro and Konso area of southern Ethiopia.

\subsubsection{Resistance to insect pests}

Majority of the respondent farmers (36.1\%) reported that Dima variety was often affected by pest. On the other hand, few respondents (6.9\%) reported that Adi variety was never affected by pest (Table 14). In addition, four key informants (33.3\%) also mentioned that Adivariety was more resistant to insect pests as compared to other varieties which agreed with the response of general informants. Furthermore, some key informants mentioned pests such as Raammoo Bili (Oroomifa) (bean bruchid), and green colored pest (bean fly, Ophiomyia spp.) of common bean varieties that affected the performance of the varieties. On the other hand, Menbere (2017) reported statistically non-significant response of common bean varieties to insect pests. The difference in response to pest of common bean varieties in this study might be due to variations in tolerance to pests and their adaptations to pest stress.

Table 14

Proportion of general respondents and response of common bean varieties to insect pests in east Hararghe Zone ( $n=72$ )

\begin{tabular}{|c|c|c|c|c|}
\hline \multirow[t]{2}{*}{ Variety } & \multicolumn{4}{|c|}{ Resistance to insect pest } \\
\hline & Never affected & Rarely affected & Sometimes affected & Often affected \\
\hline Adi & 5 & 2 & 18 & 17 \\
\hline $\begin{array}{l}\text { Adi } \\
\text { bosolia }\end{array}$ & 0 & 2 & 0 & 2 \\
\hline Bure & 0 & 2 & 3 & 3 \\
\hline Dalecha & 0 & 0 & 0 & 1 \\
\hline Dima & 0 & 3 & 14 & 26 \\
\hline $\begin{array}{l}\text { Dima } \\
\text { ashongore }\end{array}$ & 0 & 0 & 0 & 1 \\
\hline Jiner & 0 & 0 & 0 & 1 \\
\hline
\end{tabular}

\subsubsection{Seed shattering}

The ability of common bean varieties to retain the seed in their pods during maturity was explained by the respondent farmers as shown in the Table 15. Greater proportion of respondents (33.3\%) reported that Dima variety was the first one to often shatter which might be due to 
differences in genetic makeup of varieties to retain their seeds in a pod at maturity. In contrast to this result, Asrat et al. (2013) reported differences in seed shattering property of common bean varieties in which small-seeded white variety showed more shattering.

Table 15

Percentage of general respondents and seed shattering attribute of common bean varieties in east Hararghe Zone $(\mathrm{n}=72$ )

\begin{tabular}{|lllll|}
\hline Variety & \multicolumn{3}{c|}{ Shattering attribute } \\
\hline Ndi & Never shatter & Rarely shatter & Shatter some time & Often shatter \\
\hline Adi bosolia & 0 & 13 & 12 & 17 \\
\hline Bure & 0 & 0 & 0 & 4 \\
\hline Dalecha & 0 & 2 & 2 & 4 \\
\hline Dima & 3 & 1 & 0 & 0 \\
\hline Dima ashongore & 0 & 12 & 4 & 24 \\
\hline Jiner & 0 & 0 & 0 & 1 \\
\hline
\end{tabular}

\subsubsection{Seed story}

About $59.7 \%$ of respondents reported that Dima variety was the common traditional one (Fig. 6 ). Similarly, about $23.6 \%$ of respondents reported that Adi was newly introduced variety. According to the respondents, varieties such as Bure, Dalecha, Dima, Dima ashongore and Jiner were not newly introduced to the study area. This difference in seed story might be attributed due to fewer introductions of newly released varieties, less awareness of local farmers, and low income of farmers to buy the seed of new varieties. Furthermore, adaptability, resilience and tolerance of traditional varieties to environmental stresses might have proved to maintain them. Menbere (2017) also reported more number of traditional varieties in the market as compared to new (improved) varieties.

\subsubsection{Ease of harvesting}

Majority of the respondents (55.5\%) reported that Dima variety was easy to harvest at its maturity (Table 16). Contrary to this, only very few respondents reported that varieties such as Adi, Bure, Adi bosolia and Dima were difficult to harvest. This difference in ease of harvesting of varieties might be due to differences in the morphological structure and their growth habit; the determinate bush as in the case of Dima variety is easier as compared to bush climbing one as in the Adi bosolia and Dima ashongore. Similar result was reported by Rediet et al. (2017) in which bush type genotypes of common bean performed better under intercropping situation.

Table 16

Proportion of general respondents and ease of harvesting of common bean varieties in east Hararghe Zone $(n=72)$

\begin{tabular}{|llll|}
\hline Variety & \multicolumn{3}{l|}{ Ease of harvesting } \\
\hline Difficult & Easy & Very easy \\
\hline Adi bosolia & 1 & 37 & 4 \\
\hline Bure & 2 & 3 & 0 \\
\hline Dalecha & 0 & 6 & 0 \\
\hline Dima & 1 & 0 & 1 \\
\hline Dima ashongore & 0 & 0 & 2 \\
\hline Jiner & 0 & 1 & 0 \\
\hline
\end{tabular}

\subsubsection{Ease of food preparation}

More number of respondents (13.8\%) reported that the grain of Dima was very easy to prepare food such as 'Nifuro' in Amharic or 'Shoomo' in Oroomifa (the boiled grain) as compared to Adi variety (6.9\%). This difference in ease of food preparation might be due to lesser time required to boil the grain of Dima as compared to others. Similarly, Betelhem et al. (2020) also reported that common bean varieties such as Chele Gobo in south west and Key Boloqe in the north east Ethiopia were preferred to prepare food as compared to other varieties.

Page $12 / 21$ 


\subsubsection{Food taste}

More number of respondents (18.1\%) reported that Dima variety followed by Adi had very good taste when used as food (Fig. 7). Some key informants also mentioned that Dima variety was preferred to make Shoomo (Oroomifa) (boiled grain) due to its color mix with maize grain as a local food while they mentioned that the grain of Adi variety was preferred to make 'ShiroWot' (Amharic) (a sauce made from the flour of the grain) due to its aroma. The preference of the grain of different varieties for different types of food preparation might be attributed to the food culture, the appearance and the aroma of the boiled grain. Similar to this result, Abraham et al. (2016) reported that red seed beans are preferred because the red color imparts to the food after cooking. In contrast, Betelhem et al. (2020) reported that Dalecha Boloqe (cream colored seed bean) was preferred by farmers due to its good taste and color.

\subsubsection{Soil fertility requirement}

Majority of respondents (56.9\% and 51.4\%, respectively) replied that Dima and Adivarieties require medium soil fertility for their optimum growth and development (Fig. 8). Only few respondents also reported that Adi bosolia, Bure, Dima ashongore and Jiner varieties require medium soil fertility. All key informants also reported that common bean requires medium soil fertility in black soils. This might be due to its ability to fix nitrogen which satisfies its nitrogenous fertilizer demand with less or no application of chemical fertilizer. Menbere (2017) also reported that common bean requires low input but it gives high yield. The report of GRDC (2014) also shows that the average amounts of nitrogen fixed range from 60 kilograms $\mathrm{N}$ per hectare for lentils to $130 \mathrm{~kg} \mathrm{~N} /$ ha for lupins.

\subsection{Values of Common bean Varieties}

\subsubsection{Importance as food}

Majority of respondent famers (40.3\%) considered the grain of Adi variety very important as food (Fig. 9). On the other hand, 23.6\% of the respondents reported that the grain of Dima variety was extremely important as food. The extremely importance of Dima variety might be due to its attractive color when cooked with maize grain, its less time requirement when cooked and its property to mature earlier. Moreover, most key informants (75\%) reported that Dima variety was used to make Nifro (boiled grain) because of its attractive mixture color appearance with maize grain and Adi variety was used to make Wot (sauce of the grain flour) because of its aroma. Similarly, Betelhem et al. (2020) showed that red varieties (Chele Gobo in the south west and Key Boloqe in the northern Ethiopia have an appealing color and good taste, mature in a shorter time, and can be processed for food more quickly than others.

\subsubsection{Importance as a source of income}

More number of respondents (22.2\%) replied that the grain of Adi variety was extremely important as a source of income (Fig. 10) which might be due to the ability of Adi grain to fetch the premium price in the market and its demand as an export commodity in the country. In conformity with this result, Betelhem et al. (2020) also reported that in the northern Ethiopia, the white variety (Nech Boloqe) is grown primarily for export markets being an important source of income. Likewise, Menbere (2017) also reported that white variety of common bean is mostly produced for export purpose to the European Union (EU) and United States of America (USA).

\subsubsection{Importance as fodder}

Greater number of respondents reported that all common bean varieties were used as a source of fodder (Fig. 11). Only few respondents (2.7\%) considered Adi variety as extremely important source of fodder. Majority of key informants (75\%) also reported that Dima variety gives more residues which are commonly fed to domestic animals such as cattle, sheep, goat and donkey after threshing. The high production of residues might be due to its high biomass production and more palatability as compared to the other varieties. Menbere (2017) also reported that the residues of common bean were highly used as a source of livestock feed. In addition, Betelhem et al. (2020) reported the importance of common bean as fodder is greater than grass pea (Lathyrus sativus) in the north eastern Ethiopia.

\subsubsection{Soil fertility management}

All general and key informants reported that growing common bean varieties had positive impact on the soil fertility status. According to their perception, growing of common bean in rotation, as a sole or intercropping with other crops such as sorghum and maize improves the fertility status of the soil. The report of Menbere (2017) also agrees with this result that crop rotation with common bean was practiced by the majority of farmers to improve soil fertility of the farmlands. Betelhem et al. (2020) also reported that through intercropping and rotation, common bean contributes to soil fertility enhancement and therefore plays an essential role in agro-ecological intensification.

\subsubsection{Grain price}

Respondent farmers in the study area used to sell the grain of common bean varieties and the price for each variety is indicated in the Table 17. Higher number of respondents (36.1\%) reported that the grain of Adi and was sold at a price ranging from 10-15 birr per kg. This might be due

Page 13/21 
its high demand for export market. Tura et al. (2018) also reported similar results in which some landraces of common bean (Abbajolle, Wajjo and Walensu) were sold at high price than others (Bushay, Dima and Gumaray). Betelhem et al. (2020) also reported that both white and red varieties are more common in the market and sold at high prices in south western and north eastern parts of Ethiopia.

Table 17

Proportion of general respondents and grain price of common bean varieties in east Hararghe Zone $(n=72)$

\begin{tabular}{|lllll|}
\hline Variety & \multicolumn{3}{l}{ Price (ETB/kg) } & \\
\hline & $5-10$ & $10-15$ & $15-20$ & $20-25$ \\
\hline Adi & 3 & 26 & 3 & 1 \\
\hline Adibosolia & 0 & 1 & 1 & 0 \\
\hline Bure & 0 & 2 & 1 & 0 \\
\hline Dalecha & 1 & 0 & 0 & 0 \\
\hline Dima & 6 & 25 & 5 & 0 \\
\hline Dimaashongore & 0 & 1 & 0 & 0 \\
\hline Jiner & 0 & 1 & 0 & 0 \\
\hline
\end{tabular}

ETB $=$ Ethiopian Birr

\subsection{Production Constraints of Common Bean Varieties}

As shown in Fig. 12 below, insect pests were reported as the leading (81.9\%) production constraint of common bean. On the other hand, the problem of wild animals and flooding were mentioned as equally important. Three of the twelve key informants also reported that the common insect pests in the study area include Raammoobilli (bean bruchid, Acanthoscelides obtectus)) and bean fly (Ophiomyia spp.). They also mentioned some common bean diseases such as Sharuf (white mold, Sclerotinia sclerotum) and Wag (rust). Those key informants also mentioned some weed species such as Namale (Parthenium hysterophorus), Hoolagabis (Commelina benghalensis), Qoresufi (Argemone ochroleuca) and Hadda (Guizotia scabra), as constraint to the production of common bean in the area. There is lack of pesticides and herbicides, and low awareness of farmers how to protect and control pests and weeds at their threshold. Moreover, erratic and low rainfall and lack of integrated disease management system might have reduced the productivity of the crop. Similarly, Menbere (2017) reported insect pests as a major constraint of common bean production. Girma (2016) also reported low soil nitrogen and phosphorus levels, and acidic soil conditions as important constraints for bean production in most cropping areas of Ethiopia. Contrary to this finding, Katungi et al. (2010) reported that drought was by far the most important common bean production constraint, with a probability of occurrence estimated at $38 \%$ in Ethiopia and 60\% in Eastern Kenya.

\subsection{Gender Roles in Production and Post-Harvest Management of Common bean}

According to the response of respondent farmers in the study area, most agronomic practices such as plowing, hoeing, land leveling, seed sowing and weeding were undertaken by male adults (Table 18). Only few numbers of male elders, female adults, female and male children were involved in aforementioned agronomic practices. Likewise, majority of respondents reported that harvesting (85\%), threshing (71\%), cleaning $(65 \%)$ and storing (65\%) practices were also performed by male adults (Table 18). On the other hand, all of the respondents mentioned that the activity of preparing food (cooking) from common bean was done by female adults. The number of female farmers (36\%) was also mare than the number of male farmers (4.2\%) in seed marketing. This might be due to the tradition and culture adapted in the area in which most indoor activities are carried out by female farmers while most outdoor activities are undertaken by male farmers. In line with this result, Betelhem et al. (2020) reported clear division of labor between male and female in the family in which male farmers were primarily responsible for ploughing and female farmers were responsible for food preparation. Nahusenay and Tesfaye (2015) also reported that about $90 \%$ of food processing, water fetching, fuel and wood preparing for household consumption are mostly done by women due to the norms developed as a culture in the community. Conversely, Mukasa and Salami (2015) reported that women are more likely to work in agriculture than their male counterparts in Tanzania and Uganda. 
Table 18

Proportion of general respondents, agronomic and post-harvest practices of common bean and role of gender in east Hararghe Zone $(n=72)$

\begin{tabular}{|c|c|c|c|c|c|c|c|}
\hline Activity & Gender & Frequency & $\%$ & Activity & Gender & Frequency & $\%$ \\
\hline \multirow[t]{3}{*}{ Ploughing } & Female adults & 3 & 4 & \multirow[t]{3}{*}{ Harvesting } & Female adults & 26 & 36 \\
\hline & Male adults & 70 & 97 & & Male adults & 61 & 85 \\
\hline & Male elders & 3 & 4 & & Male elders & 1 & 1 \\
\hline \multirow[t]{5}{*}{ Hoeing } & Female adults & 1 & 1 & \multirow[t]{4}{*}{ Threshing } & Female adults & 24 & 33 \\
\hline & Female children & 1 & 1 & & Female children & 2 & 3 \\
\hline & Male adults & 68 & 94 & & Male adults & 51 & 71 \\
\hline & Male children & 1 & 1 & & Male children & 2 & 3 \\
\hline & Male elders & 3 & 4 & \multirow[t]{3}{*}{ Cleaning } & Female adults & 25 & 35 \\
\hline \multirow[t]{3}{*}{ Land leveling } & Female adults & 1 & 1 & & Female children & 1 & 1 \\
\hline & Male adults & 68 & 94 & & Male adults & 47 & 65 \\
\hline & Male elders & 3 & 4 & \multirow[t]{3}{*}{ Storing } & Female adults & 25 & 35 \\
\hline \multirow[t]{2}{*}{ Sowing } & Male adults & 71 & 99 & & Female children & 1 & 1 \\
\hline & Male elders & 1 & 1 & & Male adults & 47 & 65 \\
\hline Weeding & Male adults & 72 & 100 & Cooking & Female adults & 72 & 100 \\
\hline
\end{tabular}

\section{Conclusion}

Through field survey, seven farmers' varieties of common bean were identified. Farmers mostly grow common bean and other legume species either by rotation or by intercropping with cereals and other crops. Farmers of mid to high income allocate more area to grow common bean than low income farmers. Most agronomic and post- harvest activities of common bean are carried out by male adults whereas seed marketing and food preparation activities are undertaken by female adults. The diversity of farmers' varieties is more in tepid, moist mid highlands (M3) agroecology as compared to tepid, sub-humid mid highlands (SH3) agro-ecology. Adi and Dima varieties of common bean are the main sources of food and income, respectively. These varieties are also more tolerant to production constraints such as drought, disease, pest and others. In general, the diversity of farmers' varieties is low and should be maintained for agro-ecological intensification and soil fertility management.

\section{Declarations}

\section{ACKNOWLEDGEMENTS}

The authors would like to acknowledge the facility and moral support from Wachemo University and Haramaya University. We are also grateful to thank the farmers we interviewed and the zonal, district, and sub-district administrators who facilitated the research. Our gratitude also goes to language translators during survey work. We would also like to thank the McKnight Foundation Legume Diversity Project for financial and technical support.

\section{References}

1. Abraham Mulu, Andergachew Gedebo and Hussien Mohammed. 2016.Participatory Variety Evaluation of Red Common Bean (Phaseolus vulgaris L.) in Boricha District of Southern Ethiopia. Advances in Crop Science and Technology 4(5), doi: 10.4172/2329-8863.1000237

2. Agete Jerena .2014. An analysis of factors influencing participation of smallholder farmers in red bean marketing in Halaba special district, Ethiopia. MSc. thesis at university of Nairobi. pp.5-9.

3. Amanuel Alemu, Amisalu Nebiyu, and Merkeb Getachew.2018. Growth and yield of common bean (Phaseolus vulgarisL.) cultivars as influenced by rates of phosphorus at Jimma, Southwest Ethiopia. Journal of Agricultural Biotechnology and Sustainable Development,10(6), pp. 104-115 https:// DOl.org/10.5897/JABSD2018.0312

4. Asrat Asfaw .2011. Breeding for drought tolerance by integrative design: the case of common bean (Phaseolus vulgaris L.) in Ethiopia. PhD thesis, Wageningen University, The Netherlands, 187pp. 
5. Asrat Asfaw, Almekinders C. J. M., Struik P. C. and Blair M. W.2013. Farmers' common bean variety and seed management in the face of drought and climate instability in southern Ethiopia. Academid Journals 8:22 pp 1022-1037

6. Awel Beshir1, Demeke Lea and Tesfaye Belay. 2021.Evaluation of Recently Released Common Bean (Phaseolus vulgaris L.) Varieties in Kafa and Sheka Zones, South Western Ethiopia. Asian Journal of Plant Science and Research, 2021, 11 (2):33-36

7. Betelhem Abera, Menbere Berhane, Amsalu Nebiyu, Morgan L. Ruelle, Alex McAlvay, Zemede Asfaw, Abush Tesfaye and Zerihun Woldu.2020. Diversity, use and production of farmers' varietiesof common bean (Phaseolus vulgaris L., Fabaceae) in southwestern and northeastern Ethiopia.Genet Resource and Crop Evolution. https://doi.org/10.1007/s10722-019-00877-4

8. CSA (Central Statistical Agency). 2007. Statistical Tables for the 2007 Population and Housing Census, Addis Ababa, Ethiopia.

9. CSA (Central Statistic Authority). 2016.Agricultural Sample Survey Report on Area andProduction of Major Crops for Private Peasant Holdings for Meher Season of 2015/16, Addis Ababa, Ethiopia

10. CSA (Central Statistic Authority).2017. Agricultural Sample Survey Report on Area andProduction of Major Crops for Private Peasant Holdings for Meher Season of 2016/17, Addis Ababa, Ethiopia

11. Darkwa, K., Daniel Ambachew,Hussien Mohammed, AsratAsfaw and Mathew B.W.2016. Evaluation of common bean (Phaseolus vulgaris L.) genotypes for drought stress adaptation in Ethiopia. The crop Journal 4: 367-376.

12. EHZAO (East Hararghe Zone Agriculture Office).2017. Annual report of Post-Harvest Crop Yield Assessment, Harar, Ethiopia Ecoport.2013. Ecoport database. Ecoport

13. Girma Kibatu.2016. Minerals and Trace Elements in the Soil-Plant-Animal Continuum in Ethiopia: a Review. African Journal of Food, Agriculture, Nutrition and Development 6(4):11219-11235. DOl: 10.18697/ajfand.76.15580

14. GRDC (Grains Research and Development Corporation). 2014.Nitrogen fixation of crop legumes: basic principles and practical management.

15. Heuzé, V., G. Tran., P. Nozière., andLebasF. 2015. Common bean (Phaseolus vulgaris). Feedipedia, a programme by INRA, CIRAD, AFZ and FAO. https://www.feedipedia.org/node/266

16. Hirpa Legesse, Nigussie Dechassa, Setegn Gebeyehu, Geremew Bultosa and Firew Mekbib 2013. Response to Soil Acidity of Common Bean Genotypes (Phaseolus vulgaris L.) Under Field Conditions at Nedjo, Western Ethiopia. Science, Technology and Arts Research Journal 2(3): 3-15.

17. Jibril Temesgen, TayeKufa and Zeleke Wondimu.2015. Effect of Plant Density of Hybrid Maize and Common Bean Varieties on the Productivity of Intercropping System at Jimma, South West Ethiopia. Global Journal of Life Sciences and Biological Research 1(1):9-19

18. Jose, F., S. Mohammed, G. Thomas, G. Varghese, N. Selvaraj and M. Dorai. 2014.Genetic diversity and conservation of common bean (Phaseolus vulgaris L., Fabaceae) landraces in Nilgiris

19. Katungi, E., A.Farrow, T. Mutuoki, S.Gebeyehu, D.Karanja, F.Alemayehu, L.Sperling, S.Beebe, J.C. Rubyogo and R. Buruchara .2010.Improving Common Bean Productivity: An Analysis Of Socio-Economic Factors In Ethiopia And Eastern Kenya. Baseline Research Report

20. Menbere Berhane.2017. Diversity in Farmers' Varieties (Landraces) of Common Bean (Phaseolus vulgaris L., Fabaceae) in South Wollo and East Gojjam Zones of Amhara Region, Ethiopia.M.Sc.Thesis, Addis Ababa University, Ethiopia

21. Mengesha Kebede.2015.Development of Sustainable Weed Management Practices for Common Bean (Phaseolus vulgaris L.) in Eastern Ethiopia. PhD Dissertation, Haramaya University, Ethiopia

22. Mukasa, A. and Salami. A. O. 2015. Gender productivity differentials among smallholder farmers in Africa: A cross-country comparison

23. Nahusenay Abate and Tesfaye Tiruneh .2015. Roles of rural women in livelihood andsustainable food security in Ethiopia: A case study from DelantaDawunt District, North Wollo Zone. International Journal of Nutrition and Food Science 4(3):343-355.

24. Pathania, A., Sharma P.N., Sharma O.P., Chahota R.K., AhmadB., Sharma P. 2006. Evaluation of resistance sourcesand genetics of resistance in kidney bean to Indianvirulences of Colletotrichumlindemuthianum. Euphytica 149:97-103

25. Porch, T. G., Beaver J. S., Debouck D. G., Jackson S. A., Kelly J. D. and Dempewolf H. 2013. “Use of Wild Relatives and Closely Related Species to Adapt Common Bean to Climate Change". Agronomy 3 (2):433-61

26. Rediet Abera, Walelign Worku and Sheleme Beyene.2017. Performance variation among improved common bean (Phaseolus vulgaris $L$.) genotypes under sole and intercropping with maize (Zea mays L.). Asian Journal of Agriculture 12(6), pp. 397-405

27. Ruelle, M. L. I, Zemede Asfaw, AsmareDejen, Sarah Tewolde-Berhan, Amsalu Nebiyu, TamadoTana and Power A. G.2019. Inter- and intraspecific diversity of foodlegumes among households andcommunities in Ethiopia

28. Teame Gereziher, Ephrem Seid and Getachew Bisrat.2017. Performance evaluation of common bean (Phaseolus vulgaris L.) varieties in Raya Valley, Northern Ethiopia. African Journal of Plant Science 11(1), pp. 1-5, January 2017

29. TesfayeTafesse.2013. Research-inspired Policyand Practice Learning in Ethiopia and the Nile Region: A case study in four villages ofEastHararghe zone, Oromia Region

Page $16 / 21$ 
30. Tigist Shiferaw, Melis R., Sibiya J. and Gemechu Keneni.2018. Evaluation of different Ethiopian common bean, Phaseolus vulgaris(Fabaceae) genotypes for host resistance to the Mexican bean weevil, Zabrotes subfasciatus (Coleoptera: Bruchidae). International Journal of Tropical Insect Science 38: 115https://doi.org/10.1017/S1742758417000248

31. Titay Zeleke, Fekadu Beyene, Temesgen Deressa, Jemal Yousuf and Temesgen Kebede. 2021. Vulnerability of Smallholder Farmers to Climate Change-Induced Shocks in East Hararghe Zone, Ethiopia. Sustainability 13(4):2162

32. Tura Bareke, Zemede Asfaw,Zerihun Woldu, Medvecky B., and Birhanu Amssalu.2018.Diversity of common bean (Phaseolus vulgaris L., Fabaceae) landraces in parts of southern and eastern Ethiopia. Advances in Plants \& Agriculture Research8(6):449-457

33. Zelalem Fisseha.2015. Genetic Diversity and Population Structure of Common Bean (Phaseolus Vulgaris L.) Germplasmfrom Ethiopia. A Thesis Submitted to the School of Graduate Studies College Of Natural Sciences, Addis Ababa University, Ethiopia

\section{Figures}

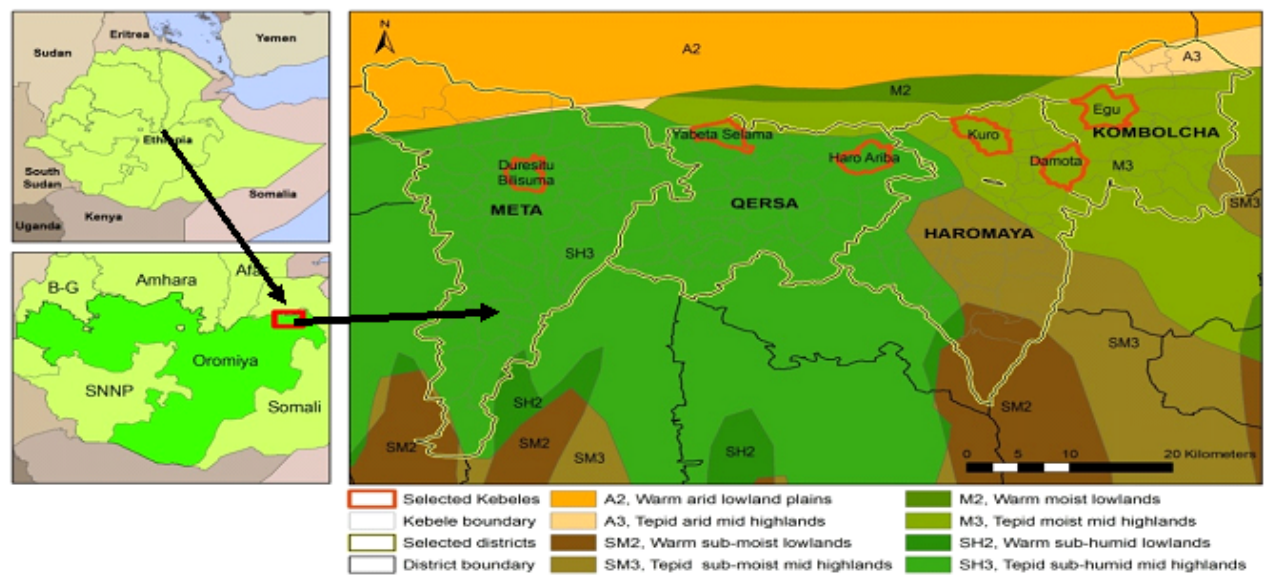

Figure 1

Map of selected Woredas and Kebeles in east Hararghe Zone of Oromia Regional state, eastern Ethiopia Woreda = district, Kebele $=$ sub-district Note: The designations employed and the presentation of the material on this map do not imply the expression of any opinion whatsoever on the part of Research Square concerning the legal status of any country, territory, city or area or of its authorities, or concerning the delimitation of its frontiers or boundaries. This map has been provided by the authors.

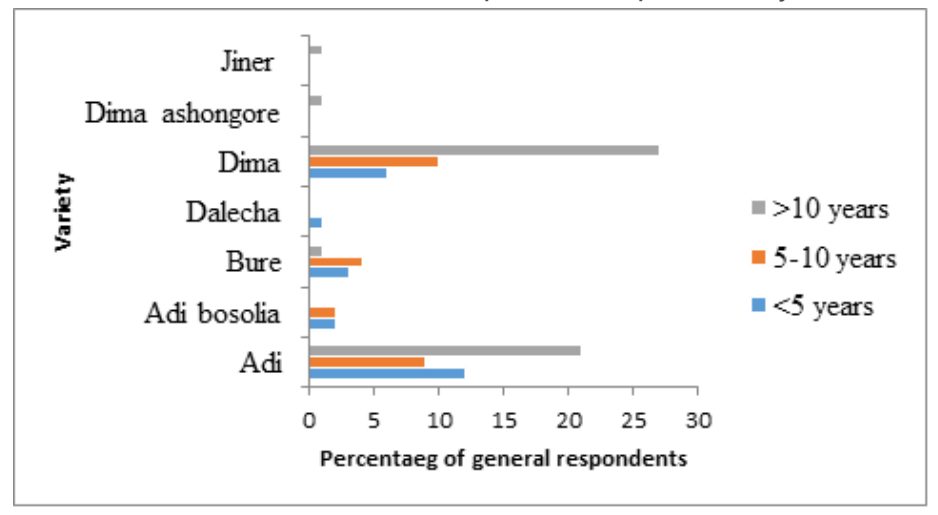

\section{Figure 2}

Percentage of general respondents and range of growing years of common bean varieties in east Hararghe Zone ( $n=72)$ 


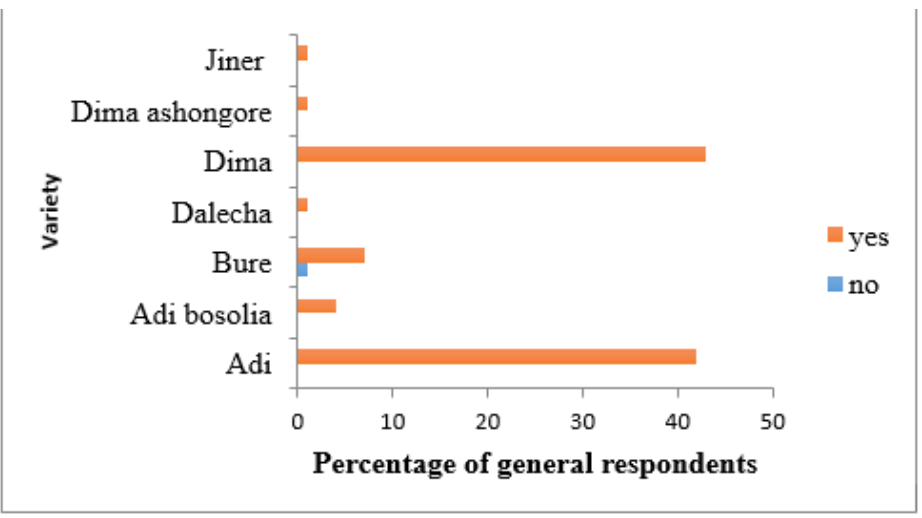

Figure 3

Percentage of general respondents and seed marketing practice of common bean varieties in east Hararghe Zone ( $\mathrm{n}=72$ )

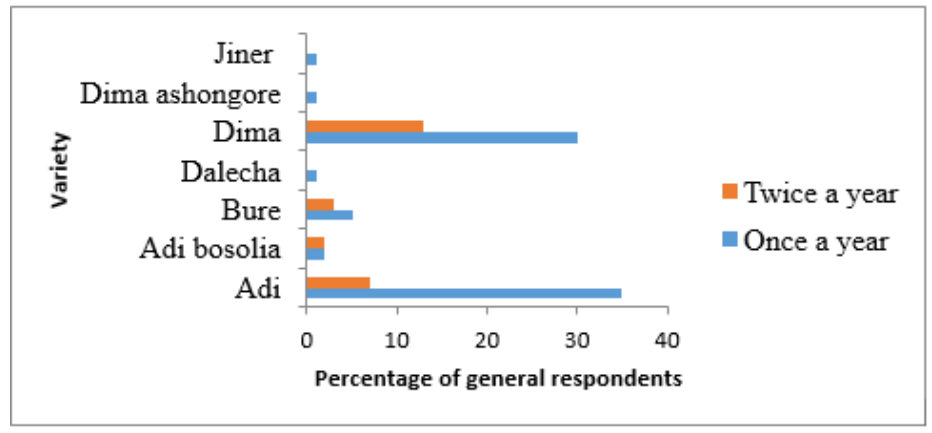

Figure 4

4 Percentage of general respondents and frequency of growing seasons of common bean varieties in east Hararghe Zone ( $\mathrm{n}=72$ )

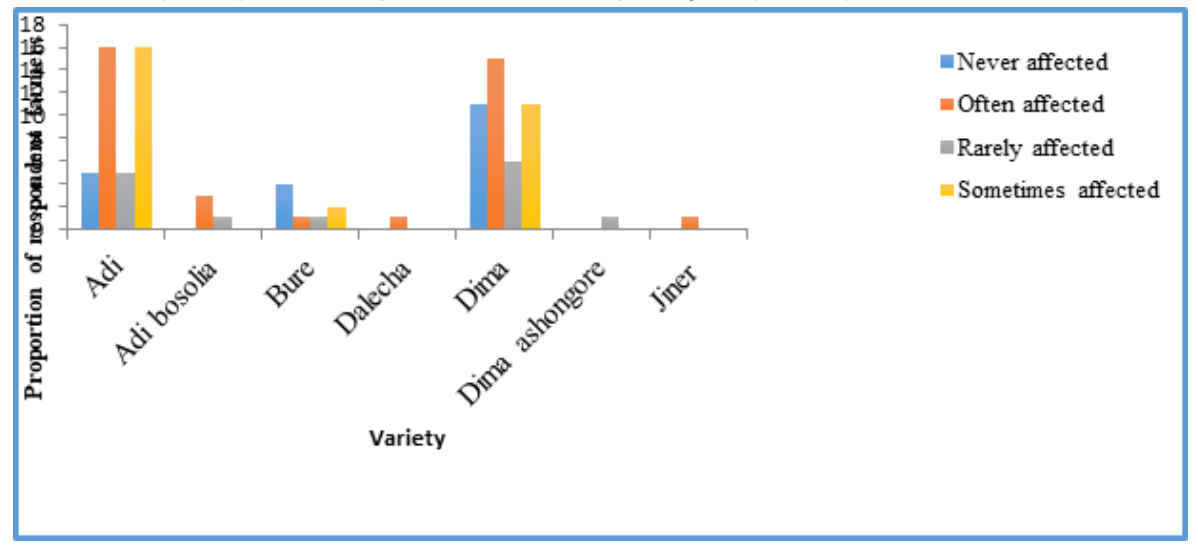

Figure 5

Proportion of general respondents and response of common bean varieties to diseases in east Hararghe Zone ( $n=72)$ 


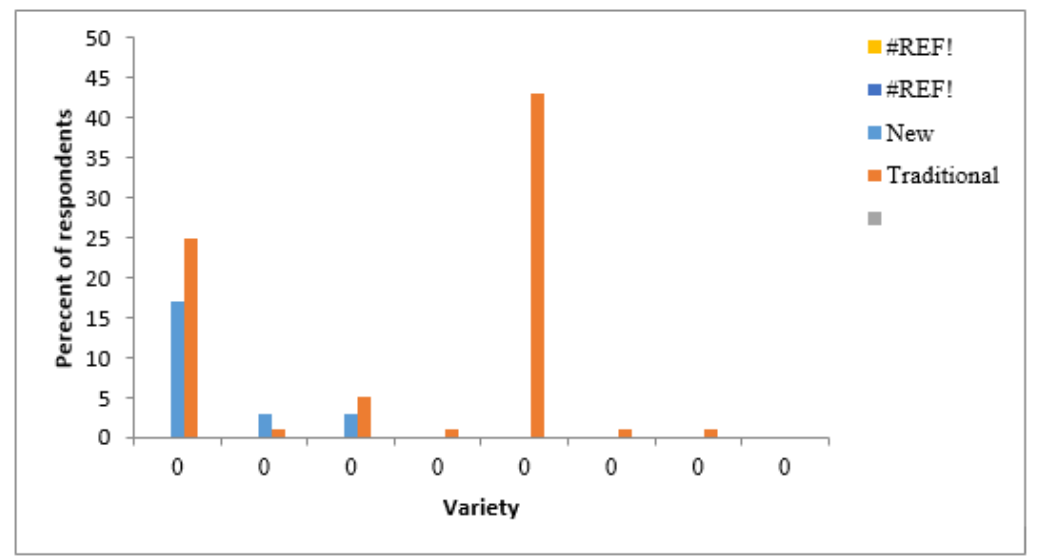

Figure 6

Percentage of farmers growing different common bean varieties in east Hararghe Zone in 2018 cropping season $(n=72)$ New $=$ newly introduced, Traditional = grown for many years

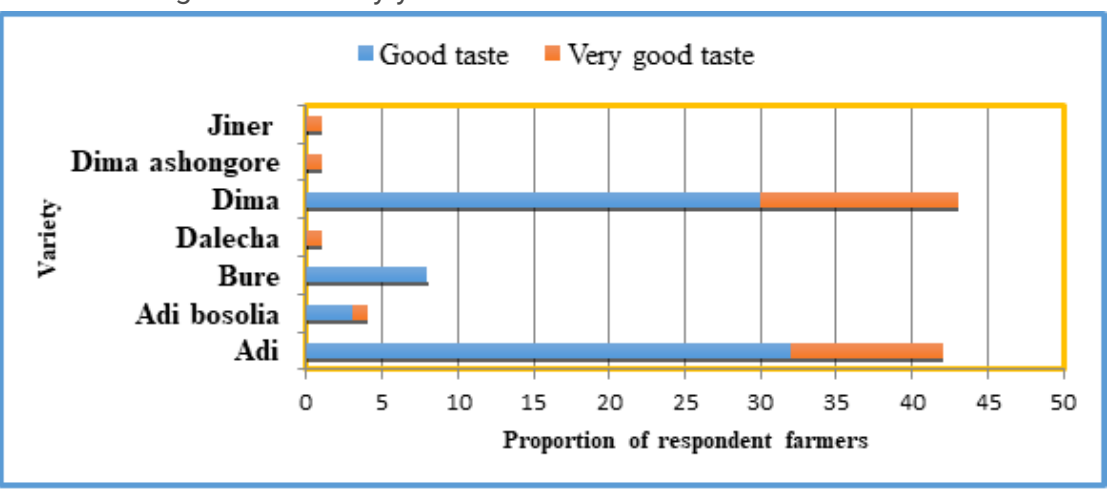

\section{Figure 7}

Proportion of general respondents and food taste of common bean varieties in east Hararghe Zone $(n=72)$

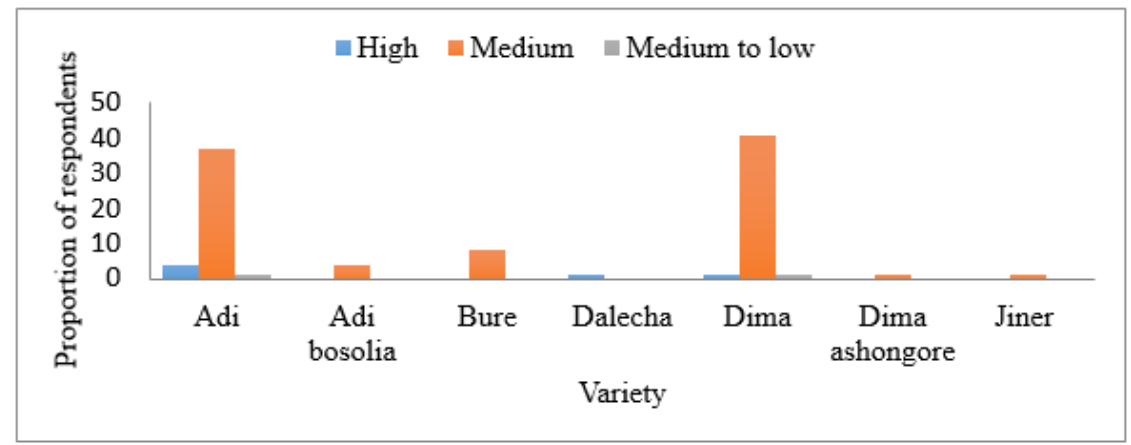

Figure 8

Proportion of general respondents and soil fertility requirement of common bean varieties in east Hararghe Zone ( $\mathrm{n}=72$ ) 


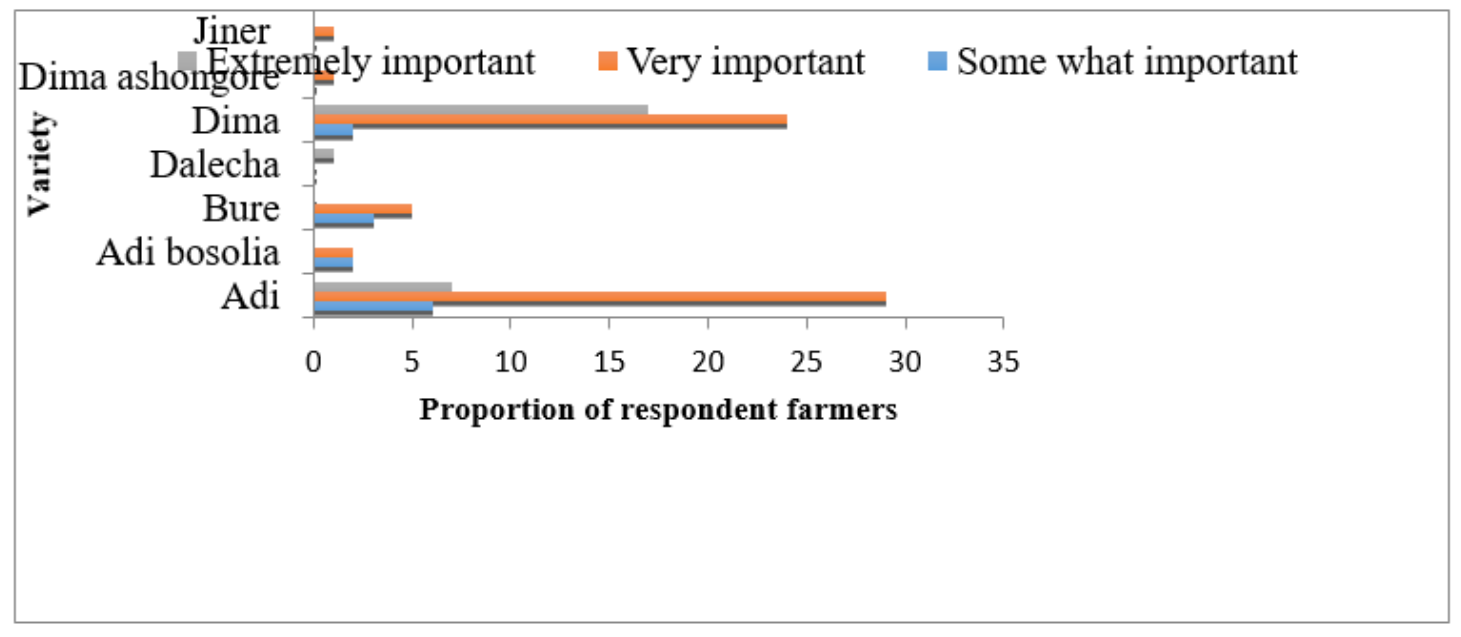

\section{Figure 9}

Proportion of general respondents and importance of common bean varieties as food in east Hararghe Zone $(n=72)$

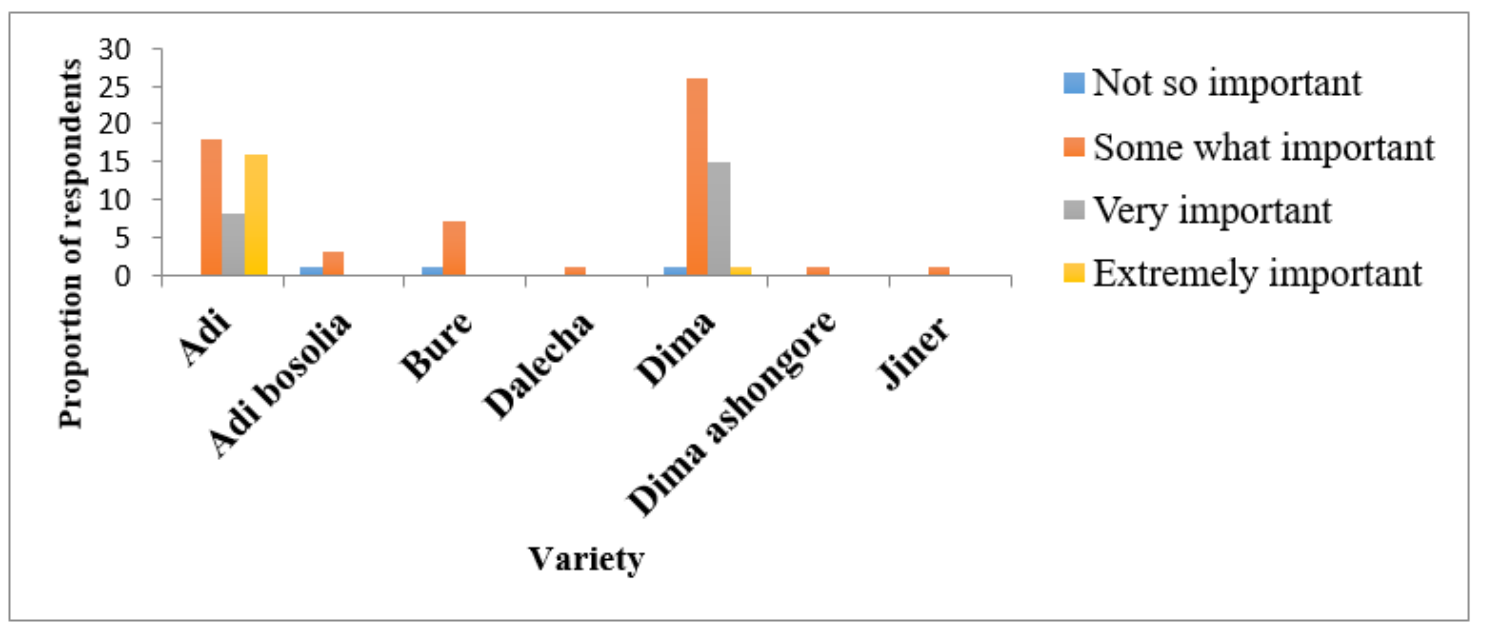

\section{Figure 10}

Proportion of general respondents and importance of common bean grain as a source of income in east Hararghe Zone ( $\mathrm{n}=72$ )

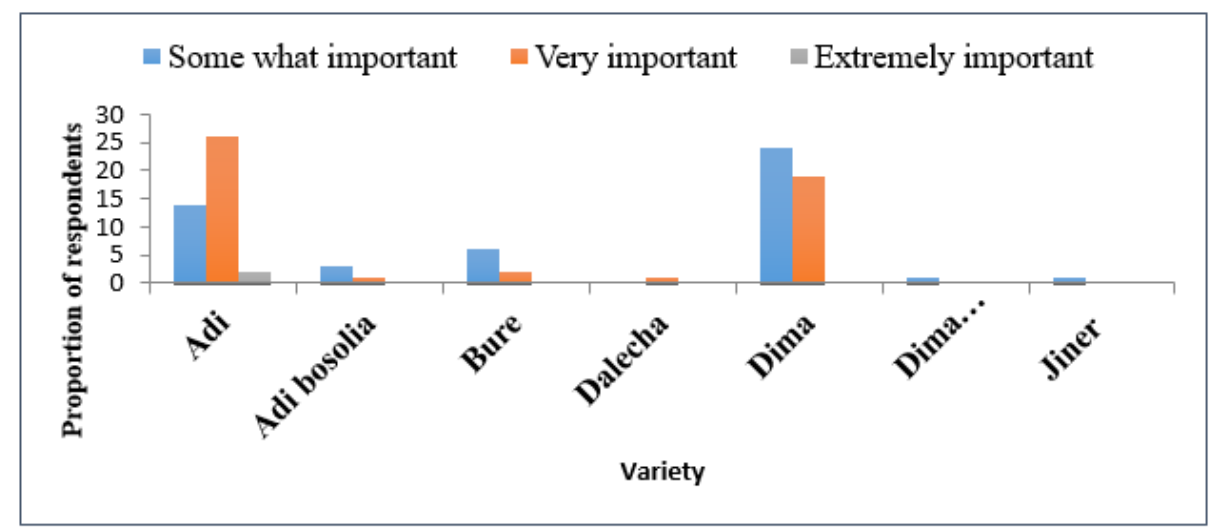

\section{Figure 11}

11 Proportion of general respondents and importance of common bean varieties as a source of fodder in east Hararghe Zone ( $\mathrm{n}=72$ ) 


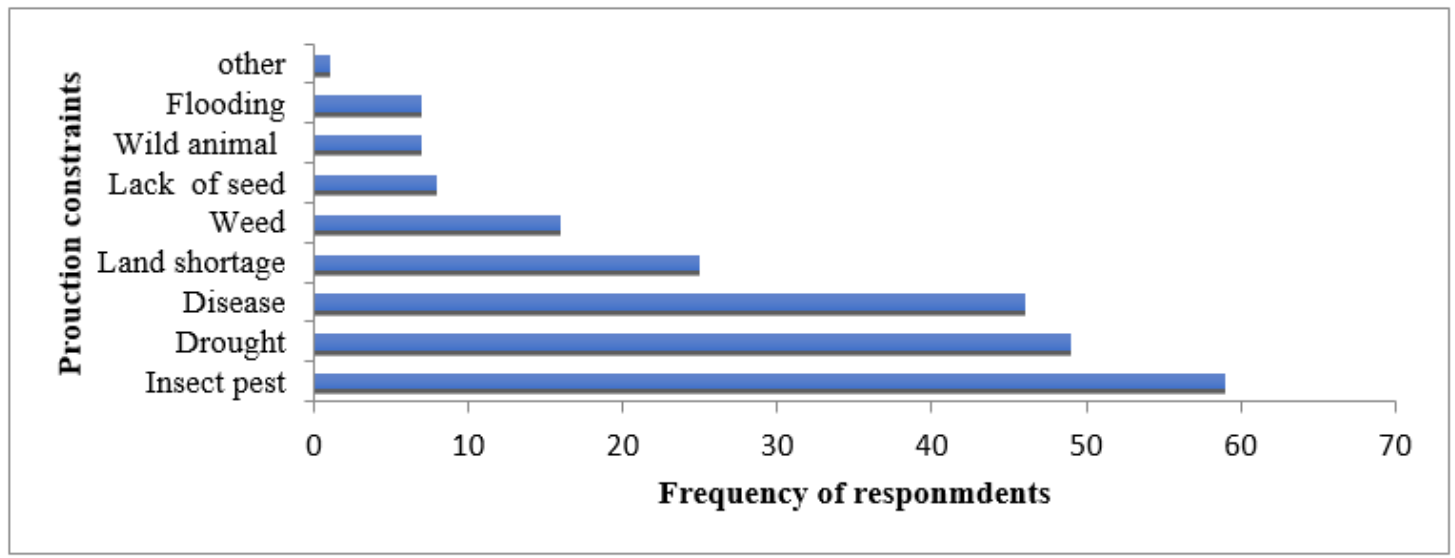

Figure 12

Proportion of general respondents and production constraints of common bean in east Hararghe Zone $(n=72)$ 